\section{CALCULI IN THE BLADDER,}

OX THE ADVANTAGES OF, AND OBJECTIONS TO, THE USE OF THE

PERCUTEUR COURBE A MAITEAU.

With a Case illustrating its efficiency when the Prostate Gland is enlarged.

By Baron Hevrtelote, M.D.

\section{To the Editor of The LanceT.}

Sir,-To comminute a stone in the interior of the bladder by means of a hammer, is a process sufficiently new and unlooked for, to render it difficult for some at first to beliere that it can be exempt from danger; and it is a matter of great difficulty to do away with the unfavourable impressions which are mostly made by those who, without having on the subject very accurate ideas, launch out into conjecture, and reason on typotheses instead of reasoning on facts.

Allow me, Sir, through the medium of your widely-circulated jounnal, to rectify some of the incorrect ideas which may have been formed respecting the percuteur courbe à marteau.

It has been said of this instrument, in the first place, that it is liable to break in the patient's blalder; secondly, that its besks were liable to separate, and so prevent it from being withdrawn; thirdly, that during the percussion with the bam mer the instrument might vibrate, and cause considerable pain; fourthly, that iduring the percussion, the fragments might fly against the bladder and injure it: fiftlily, that the instrument was not well calculated to seize the stone; sixthly, that curved instruments were useless, since straight ones always sufficed; seventhly, that it could only be employed in cases of small friable calcull; and, finally, eighthly, that it nroduced fragments but no powder, which rendered the evacuation of the stone more difficult.

$I$ will endeavour to answer all these objections, which, for the most part, were made by the members of the committer, chosen by the Institute of France, to examine my labours. In the numerous opportunities which these competent judges afforded me, 1 prored to then, by facts, that their objections were unfounded; and, in order to render myself clear and methodicul, I shall now notice and refute them one by one.

1st. Can the instrument break in the patient's bladder?

I have placed several instruments in the point fixe of the rectangular bed, and all $\mathrm{my}$ efforts to break them have proved unsuc- cessful. When I employed a hammer of considerable weight, I succeeded in forcing the branches apart, but only when I placed between them some tough, unyielding substance, such as a piece of wood or steel. Whenever I acted upon a culculus, however hard, it always gave way. I asked several persons to use their utmost efforts to break an instrument; but their attempts were equally fruitless. These experiments prove, that it is not possible to leave a portion of the percuteur courbe in the blad. der; for the most determined resolution to produce a fracture of this instrument, outside the bladder, is unavailing. This will be readiy conceived, when it is known, that no part of it is tempered.

2ndly. Are the beaks liable to separate and to present the instrument from being withdrawn?

Without doubt-if, as I said in the former expesiment, a hammer be employed not in proportion to the power of resistance of the instrument. But, as I never operate on a patient with an instrument which has not previously been submitied to repeated trials with a hammer twice the weight of the one cmploued in the operation, it will be admitted that a separation of the branches need not be feared, since there is not in the band of the operator suficient power to produce it. All will, I think, admic, that it was not possible at once to perceive all the properties which were required to reader this a good and serviceable instrument, or to discover what was the most advantayeous con. struction to be adopted in its numerous details ; it was only by long and perserering study that such a knowletge was to be acquired, and this explains why, in one of the irist attempts that I made with the percuteur, the branches were warped. At that time I was inexperienced,-I employed a bammer much too heavy, and the instrument itself was imperfect, and bore but little resemblance to those which I now make use of. The proof of this is, that in the presence of the committee closen by the Acadeny, I comminuted hard and voluminous calculi, without the instrument yielding in the least. For upwards of a year, I have been constantly engaged in seehing to distribute the force equally and advantageously in the different parts of the percuteur; for this instrument being resiricted to the narrow linaits of three and a half or four lines, it is in this equable distribution (so difficult to obtain) that its power and perfection consist. Sixty or seventy different models have been constructed, in order to discover in which the greatest power for breaking could be united to the greatest delicacy for seizing. And it is only after making the successive alterations which these trials suggested, that the 


\section{BARON HEURTELOUP'S REFUTATION OF THE OBJECTIONS}

instrument was brought to its present state of perfection.

I have studied the force of resistance of the percuteur, as regards its construction and the bodies to be acted upon. I have submitted it to varied trials with hammers differing in weight, lever, and form, with solid and elastic handles ; and, lastly, I have examined, on real calculi, the comparative effect of slow or sharp, gentle or hard blows ; and $I$ discovered that even this part of the by operation, apparently so simple, had its difficulties and secrets. To understand this better, it is only necessary to consider the ease and nicety with which a practised hand detaches and works large pieces of fint, whilst another man, howsoever clever, if without practice, fatigues himself by efforts as clumsy as they are useless, and for a long time vainly trits to execute what appeared so simple and easy. Thus in conclusion, we find that there is no danger of producing the separation of the branches of the percuteur: 1st, From the far greater perfection of the instrument as regards its construction. 2dly, From the incapability of the operation to cause this separation, on account of the lightness of the hammer he employs. And Srdly, From the additional knowledge acquired of the manner of striking that is most likely to break down calculi, which, from their shape and toughness, would perhaps resist the efforts of an inexperienced operator. As a last proof, I might state, that I operate nearly every day with the percuteur without ever finding the branches give way.

$3 d l y$. During the percussion does the instrument vibrate so as to cause considerable pain to the patient?

This objection is a very natural consequence of the series of ideas which must have been formed concerning an operation, consisting in conveying into the interior of the bladder the powerful impetus of a hammer. Were I not the author of this operative process, it would be one of the first arguments that I should adduce in objection to it. I was not therefore surprised when the members of the Institute, who were examining the instrument, not only expressed doubts as to the fear of vibration, but intimated also the possibility of the entirs instrument being made to move forward by the blows of the hammer. In order to reply to these objections, I put the instrument repeatedly to the test before the members themselves; and these trials were so much the more convincing and conclusive from being made comparatively with instruments acting by progressive trituration, such as the perce-pierre. To the surprise of the examiners, the result of them was, that with the latter instrument, which they supposed scted upon stone without causing much vibrition, the bladder of the subject and water it contained, were subjected, during the action, to a considerable tremulous mo. tion,* whilst hard blows dealt on the per. cuteur with a hammer, produced no vibra. tion whatever. Although this may at first cause surprise, a moment's reflection will render it clear. An instrument acting progressively on a stone can only wolk efti. ciently by a rotatory movement, produced by the agency of a pulley; this morement must necessarily cause vibration, which is transmitted more or less to the organ in which the operation takes place. By per. cussion, on the contrary, the only manner in which the instrument can move is from before backwards, and no vibration can ensue, since no lateral movement takes place. The movement from before backwards, how. ever, is completely obviated by placing a steel wedge, constructed for the purpose, between the anterior curve of the steel bar forming the fixed point, and the correspond. ing augle of the mortice in which this bar plays. I think 1 shall have given sufficient proof of the immobility of the percuteur during the percussion, when I bare added, that during the aetion of the hammer, the patients never give the least sign of suffer. ing, but, on the contrary, all agree in stating that this is precisely the moment of the operation which is most exempt from painful sensations, and that it is considered, as it were, a moment of rest. This will be fully concurred in by those who have seen the instrument act outside the bladder, and who have placed their hand in contact with that portion of it where the comminution of the stone is effected, and have felt its perfect immobility. If, therefore, the hand placed in close contact with the instrument does not experience the least disagreeable sensit. tion during the action of the hammer, how can the bladder be in any way exposed, which, by being previously distended with water, is in no sort of contact with the in. strument?

Athly. During the percussion, do the fragments of stone fiy against the bladder and injure it ?

The bladder being filled with water, we should be rather inclined to consider this objection as chimerical; for, physically, a body propelled throught this fluid, is almost entirely deprived of the power of injury. This will be clear to those who, under the water, have tried to deal a blow with any

* It must here be remarked that, in the experi. ments to which I allude, M. Leroy (D'Etolles) was the operator, and he made use of the retangulur bed and fixed point. When the perce-pitre is ernsployed with a chevalet (hand-vice), held by an avd sistant, there not only must be very considerable vibration, but with such unsteady means of support as a hand, the entire instrument must unarounhly be $i^{n}$ continual movement. 
degree of force; the most violent efforts surgeons in London see me operate with the have but a trifling effect. I shall not dwell percuteur, and I do not think any of them any longer on this point, having said enough can say that they ever saw me introduce it to prove, that if even pieces of stone were into the bladder without directly laying hold propelled by force with the blows of the of the stone. Proofs of this have lately hammer, no inconveniences would result been given publicly at the Greenwich Hosfrom it; but this propulsion does not take pital, in a case which $I$ treated there with place, and consequently the objection of the complete success. This fifth objection is possibility of injuring the bladder falls of itself, since there can be no effect without cause. The members of the commission paid special attention to this point, and $I$ proved to them, by acting on hard and very dry calculi, well calculated to exemplify the above-named objection, that the broken pieces fall from the instrument almost perpendicularly, and receive scarcely any other impulse than that of their own specific gravity. I also proved, that these fragments are only projected at all forcibly when I begin the percussion by hard and repeated blows, witbout having first by softer strokes, loosened the layers of the stone, and so prepared it to fall more readily to pieces. In operating, I always commence by gentle blows, so that this objection is in every way answered.

5thly. Is the percuteur courbe à marteau ill ealculated to seize the stone?

I cannot better answer this objection than by following the example of a celebrated philosopher, who, to prove the existence of motion, walked. Since lithotripsy has engaged attention, some persons have receired, and still retain, an impression that an instrument with two branches cannot seize a stone properly, so as to break it down, although I have repeatedly proved the fact, by the use of the brise-coque, that such instruments are much better calculated to seize oval and flat calculi, than those composed of a greater number of branches. The percuteur, which has been similarly found fault with, furnishes another proof, that of all instruments, those with two branches seise calculi (especially oval and flat ones) with the greatest rapidity and facility; hold them with the greatest securty, and require to accomplish this, the least searching and mancuvring, and are consequently least injurious to the organ. This objection, having some weight in Paris, it was named to me by the Members of the Institute, but 1 unanswerably proved to them that it was unfounded, by first making this instrument act before their eyes, and seizing a stone 20 or 30 times in the space of a minute, and afterwards by renewing the experiment in the bladder of a dead subject, and seizing immediately at their command the stone. 'These trials were repeated 50 or 60 times before the members of the committee, with equal success. I would state as a further proof, that almost every day some of the most distinguished

\section{therefore fully cleared up.}

6 thly. Are curved instruments useless, and do straight ones always suffice?

Admitting that it is always possible to introduce straight instruments into the blad. der, this is no reason whatever why curved ones should be deemed unnecessary; for, in lithotripsy there is more to consider than the mere introduction of instrument; it is requisite, to seize the stone easily, to comminute it rapidly, and avoid irritating the bladder. It is to this end chiefly that the percuteur was constructed, and a surgeon, accustomed to use it, will I think find, that he derives these advantages from it. The curve, which is merely a consequence of what the instrument was intended to fulfil," is a secondary property, although it becomes one of the greatest importance when straight instruments cannot be introduced in to the bladder, or at least only with difficulty, and consequently with pain and danger to the patient. To contest the existence of such cases is confessing a want of experience, for they are by no means rare. I myself have met with eight or ten such cases, some of which I could not treat from want of a curved instrument. With this letter I have forwarded proof of this, in the case of a patient in whose bladder it was impossible to introduce a straight instrument. The curve is therefore a useful and valuable property of the percuteur.

7 thly. Can this instrument be employed only in cases of small friable calculi?

Such an objection as this could only be made by those who judge at once, and do not tike the trouble to perform trials, so as to speak from experience ; or else by those who have made essays with imperfect instruments, and conclude accordingly. I sufficiently proved how completely inappli. cable the objection was to the percuteur, by the experiments which I made before the members of the Institute; in three experi. ments I completely pulverised very large, and extremely hard calculi, with which I was furnished by Dr. Souberbielle, who, some years before, had extracted them by lithotomy. The cases in which I have operated, and daily operate, tend still more strongly to do away with this imaginary objection. When a stone, besides being very large, is round-a shape which pre-

* Refer to my work. Physica? Properties of Calculi, page 155 . 
sents very great resistance to the action of year ago, observed, after a day of bunting, the percuteur, an excavation is first made that his urine was deeply tinged with with the evideur à forceps, and when it is blood, and that he voided it with difficulty. thus reduced to a sort of thick shell, it This continued for three or four days, ac. yields readily to the blows of the hammer.

8thly. Does this instrument produce fragments and no powder, and thus render the evacuation of the stone more difficult?

The Baron Dupuytren particularly named and attended to this point; and I proved to him and his colleagues, by repeated ope. rations on the dead subject, that a much larger quantity of powder was produced by the action of the percuteur, than by that of instruments acting progressively on the stone; for when a portion of stone is seized between the beaks or branches of the percuteur, it is not only crushed, but the considerable portion of it which is directly between the branches, is forced out by the blows of the hammer in a sort of pulp, whilh, when dried, is found to be fine powder; the fragments formed are, in general, smaller, less numerous, and more regular in shape, than those produced by any other instrument; the reason of this is, that the effect of pereussion on a calculus is to loosen, and at last completely to disjoin, its layers, and in this manner cause it to fall to pieces; and when these pieces are again taken and acted upon by the instrument, they usually tend, by their composition, to assume a cubical shape. With the perce-pierre it is very different; for it is clear that the pieces which result from the action of an instrument that bores holes in a stone, and consequently leaves sharp edges, must necessarily be both sharp and irregulur in form.

Such are the observations which $I$ think right to publish, with the hope of doing away in some measure with the false ideas which may have been formed respecting this new and important operative process. I hope I have been sufficiently clear and concise to be understood by all ; and that I have been able to render more evident the value of an instrument which, by the nume. rous successful cases in wich it has already been employed, and the testimony given in its favour by so many distinguished members of the professiun who have seen it in use, sfems to deserre attention, and call forth the careful examination of men of science. I have the honour to be, Sir,

Your obedient servant,

Baron HeVrteloup, D.M.P.

1, Vere Street, Cavendish Square. July 28, 1832 .

Case of Mr. S., alluded to above.

Mr. S., residing in London, fifty-nine years of age, rather stout, but of a good constitition, whilst in the country about a companied by a frequent and uroent desire to make water. Mr. S. consulted his medi. cal attendant, who, by an appropriate treatment, subdued this irritable state. Four or five months afterwards Mr. S. had a second attack, but of a more serious nature. Be. sides considerable hemorrhage, there were fever and considerable pain on making water, and the urine became thick, offensive, and catarrhal; these symptoms con. tinurd with little abatement for nearly a month, when Mr. S. came to I.ondon and consulted Dr. Prout, who allayed the pain and irritability of the bladder, and obtained an almost complete cessation of the catarn; Dr. Prout then called Mr. Brodie in consultation, who sounded the patient, felt a stone, and conjointly with Dr. Prout, did me the honour to place the patient under my care.

When I proceeded to sound Mr. S, with the recto-curvilinear catheter, I found that I couid not make the instrument advance an further than the triangular ligament; I placed the catheter in Mr. Brodie's hands, who found it equally impossible, notwith. standing the must varied and careful manouvres to introduce it ints the bladder. I gave up making any further attempts with that instrument, and concluded that it bad failed on account of its small diame. ter causing its extremity to become en. tangled in the folds existing at the sujerior part of the membranous portion of the urethra; I therefore emploved a move volu. minous instrument, but with precisely the same carve as the recto-curvilinear cutheter, and it inmediately passed into the bladder. I distinctly felt a moveable calculus of small size. 'I'he bladder retained a considerable injection of water, but the bas-fond was exceedingly narrow; so much so, that I could not turn the curve of the carbeter, either to the right or to the left ; the instrument had not mare than an inch play from the anterion to the posterior part of the bladder, and sometimes this morement was completely prevented. When the in. strument was drawn towards the neck, with the curve directed upwards, the hand $e x$. perienced a sort of shouk such as would be caused by the ancle of the curve silding down a sort of elevation or step. Wishing to ascertain whetber a straight instrument could be introduced, I employed a smooth metal sound of about three lines in uiameter; but in spite of all the most perse. vering and careful mancurres, 1 could not succeed in passing it into the bladder: its point always struck against the lower part of the prostatie portion of the urethra, 
where there existed the sort of elevation | like a step. Finding that this patient could not admit straight instruments, I considered mrself fortunate in possessing the curved persuteur.

With that instrument I thought I might undertake the case with confidence. The operation was performed three days after the sounding; the stone was immediately sized and broken with the hammer; two or three fragments were afterwards talsen and comminuted, and the instrument was withdrawn. An injection brought away a considerable portion of detritus, and $\mathrm{Mr}$. S. roided in the course of the three succeeding dars the remaining portions ; I introduced the percuteur a second time without feeling the smallest fragment; three days after I sounded him with the greatest cure with the same result, and, finally, Mr. Pro. die having also sounded him without feeling any stone, we had the satisfiction to inform the patient that it was completely extracted.

Mr. Brodie and Dr. Prout were present during all the steps of this case.

Reflections.-.This is certainly a case worthy of remark, inasmuch as patients in whom there is so decided an obstacle to the introduction of straight instruments are seldom met with. The end of the straight-sound invariab!y struck against the prostatic cul de sac, and notwithstanding every possible manceurre to disengage ic, I could never succeed in surmounting this obstacle. This affords another proof, that the curve in the percuteur is not one of the least important of its advantages, since without it, in such cases, its otber properties would be useless, for before we can comminute a stone, it is necessary to arrive in the organ that contains it.

The stoutness of Mr. S. was the principal cause of the difficulty in introducing the straight instrument; and, in most cases, it is the principal cause. The bladder, in these patients, is very much raised in the pelvis, by the quantity of fat which accumulates in the lower part of this cavity; the neck of the bladder is consequently also very much raised, and as the perforation through the triangular ligament does not alter its position, it evidently follows, that astraight sound, which has passed through it, is inconveniently directed to pass through the seck of the bladder. If in these cases, the prostatic cul de sac be at all enlarged, either naturally or by the enlargement of the prostate, it is clear, that the difficuity of reaching the bludder with a straight instrument is the greater. It is in suclu cases that the curved percuteur becomes of absolute necessity.

\section{T II E L A N C E T.}

London, Saturday, August 4, 1832.

\section{A Cornespondent inquires why we} have been so silent respecting the second irruption of cholera in London, and speals of the omission as a dereliction of public duty on our part. He assumes that as soon as the second epidemic commenced we were bound to announce, and comment on, its existence, with the double object of narning foreign nations against the dangers of trading with us, and of contriiruting towards domestic safety by affording our fellowcitizens a true view of the magnitude of the existing danger. We proceed to state the reasons of our silence, and to reply to the grounds on which our correspondent supports bis complaint.

On the first oecurrence of malignant cholera in London, our readers will remember with what rabid mouths and "a la lanterne" outcries all those were assailed whose principles or occupations involved them in announcements of the actual state of the disease. Every man who dared to speak the truth was pointed out as the enemy of his country and its commerce, and was abused as energetically as if he had been the actual introducer of the pestilence. The reporters of cases were openly accused of forgery, and of being parties to a system of bribery; nay, it was even hinted in a zealous mercantile periodical (not the Times) that the cholera hunters, for want of genuine game, were trying what they could do with poison. Well, the disease worked on in its steady way. It silenced, effectualiy, a $f e w$ of the libellers, and the rest grew ashamed of their occupation, and sneaked into their native darhness out of the basking places which they had occupied in the sunny columns of the Times, and other public journals. IIeanwbile the 